\title{
Transarterial Therapies for Hepatocellular Carcinoma
}

\author{
Ezio Lanza ${ }^{a} \quad$ Matteo Donadon ${ }^{b}$ Dario Porettia Vittorio Pedicinia \\ Marco Tramarina Massimo Roncallic Hyungjin Rhee ${ }^{d}$ \\ Young Nyun Parke Guido Torzillib
}

aDepartment of Interventional Radiology, ${ }^{b}$ Department of Hepatobiliary and General Surgery, 'Department of Pathology, Humanitas University, Humanitas Research Hospital IRCCS, Milan, Italy dDepartment of Radiology, e'Department of Pathology, Yonsei University College of Medicine, Seoul, Republic of Korea

\section{Key Words}

Predictors of response after TAE and TACE for HCC - TAE and TACE for HCC

\begin{abstract}
Background: The treatment of hepatocellular carcinoma $(\mathrm{HCC})$ is still a major health issue because of its increasing incidence and because of the complexity of its management. Transarterial embolization (TAE) and transarterial chemoembolization (TACE) are two widely used locoregional therapies in the treatment of HCC, especially for unresectable intermediate and advanced HCCs. Summary: The modern use of TAE and TACE opens new scenarios for the treatment of unresectable HCC and has yielded interesting results. The present work describes the role of transarterial therapies for HCC and focuses on the different Western and Eastern approaches to the study of response predictors. Key Messages: Recent refinements in interventional radiology techniques and in HCC patient selection have facilitated better local control of the disease. The molecular profiling of HCC to predict the response to TACE and TAE will greatly help clinicians identify the optimum therapy.
\end{abstract}

Copyright @ 2016 S. Karger AG, Basel

Guido Torzilli, MD, PhD

Department of Hepatobiliary and General Surgery

Humanitas University, Humanitas Research Hospital IRCCS

Via Manzoni, 56, IT-20089 Rozzano, Milano (Italy)

Tel. +39 028224 4502, E-Mail: guido.torzilli@hunimed.eu 


\section{Introduction}

Transarterial embolization (TAE) and transarterial chemoembolization (TACE) are two widely used locoregional therapies in the treatment of hepatocellular carcinoma (HCC), especially for unresectable intermediate and advanced HCCs [1]. Although TAE and TACE are considered to be noncurative therapies, for patients with advanced HCC, no other therapy is usually recommended when surgery, percutaneous ablation, and sorafenib are unfeasible. Transarterial radioembolization (TARE) is an emerging modality that has achieved promising results for intermediate and advanced HCC [2]. The present work describes the role of transarterial therapies for HCC, starting with the techniques themselves and then focusing on the predictors of response.

\section{TACE for HCC}

The HCC vasculature is supplied by the hepatic artery rather than by the portal vein. Consequently, the segmental hepatic arteries may be selectively catheterized via retrograde femoral access, and the tumor can be visualized by means of superselective angiography. Then, different embolic agents can be injected with the aim of obliterating the vascular supply to the tumor and/or delivering drugs/radioisotopes, thereby halting or slowing tumor progression.

Liver embolization for HCC is commonly used in two main settings: (1) large unresectable HCCs unsuitable for surgery or ablation, and (2) prior to resection or to liver transplantation as a bridge therapy. In general, the best candidates are those patients with unresectable lesions without vascular invasion or extrahepatic spread and with well-preserved liver function.

Although there is no standard technique for HCC embolization, two main approaches are traditionally recognized: TACE and TAE [3]. A third, more recent and promising technique is TARE, which delivers to the tumor radioactive isotopes (eg, iodine-131-labeled lipiodol or yttrium-90 [90-Y]-tagged glass or resin microspheres).

The goal of TACE is to fill the tumor with a chemotherapeutic drug (eg, doxorubicin, epirubicin, cisplatin, or mitomycin C) using a carrier agent. Historically, the carrier agent was Lipiodol, but this has been largely replaced by drug-eluting beads TACE, which are available in different sizes [3-9]. The use of a chemotherapeutic agent requires preventive medication to avoid drug-related side effects [10]. In contrast, TAE aims to achieve superselective vascular embolization using gelatin sponge, Lipiodol, or microparticles as small as $40 \mu \mathrm{m}$ in diameter [11]. No drugs are injected during TAE, and recent evidence has suggested that no survival benefit is derived by the use of chemotherapy in TACE versus TAE [12]. In contrast to TAE and TACE, TARE achieves cell death by local radiation damage; TARE is thus considered to be a form of brachytherapy with no significant embolic effect. TARE using 90-Y-tagged glass beads has been shown to be safe and probably effective in patients with unresectable HCC [13-15]. A recent meta-analysis suggested that TARE is significantly better than TACE in terms of survival, time to progression, hospitalization time, and complication rates for patients with HCC [16]. A further role of TARE in advanced HCC patients is as a conversion treatment for patients considered otherwise unresectable or even as a bridge to transplantation [17]. Moreover, in HCC patients with a future remnant liver (FRL) inadequate for upfront surgery, TARE may represent a surrogate for portal vein embolization, combining FRL hypertrophy and tumor treatment [18].

In the HCC setting, the degree of survival advantage offered by TAE/TACE versus medical therapy is still a matter of debate. Two controlled trials have shown a survival advantage 
Table 1. Essential literature review on transarterial embolization for HCC

\begin{tabular}{|c|c|c|c|}
\hline Author, Year & Treatment & Summary & Main findings \\
\hline $\begin{array}{l}\text { Salem et al., } \\
2010 \\
{[13]}\end{array}$ & TARE & $\begin{array}{l}291 \text { patients with HCC treated } \\
\text { with }{ }^{90} \text { Y radioembolization }\end{array}$ & $\begin{array}{l}\text { Response rates } 42 \% \text { (WHO criteria) } \\
\text { and } 57 \% \text { (EASL criteria) } \\
\text { Time to progression and overall } \\
\text { survival varied by tumor stage and } \\
\text { liver function }\end{array}$ \\
\hline $\begin{array}{l}\text { Mazzaferro et } \\
\text { al., } 2013 \\
{[14]}\end{array}$ & TARE & $\begin{array}{l}52 \text { patients with intermediate to } \\
\text { advanced HCC } \\
\text { Prospective, phase II study }\end{array}$ & $\begin{array}{l}\text { Median time to progression } 11 \\
\text { months (no difference between } \\
\text { portal vein thrombosis vs. no portal } \\
\text { vein thrombosis) } \\
\text { Median overall survival } 15 \text { months } \\
\text { Various grades of reduced liver } \\
\text { function in } 36.5 \% \text { within } 6 \text { months }\end{array}$ \\
\hline $\begin{array}{l}\text { Llovet et al., } \\
2002 \\
{[18]}\end{array}$ & TACE & $\begin{array}{l}112 \text { patients with unresectable } \\
\text { HCC } \\
\text { Randomized controlled trial } \\
3 \text { treatment arms: TAE, TACE, and } \\
\text { symptomatic treatment }\end{array}$ & $\begin{array}{l}\text { TACE improved survival of strin- } \\
\text { gently selected patients }\end{array}$ \\
\hline $\begin{array}{l}\text { Lo et al., } 2002 \\
{[19]}\end{array}$ & TACE & $\begin{array}{l}80 \text { patients with unresectable } \\
\text { HCC } \\
\text { Randomized controlled trial } \\
\text { TACE vs. symptomatic treatment }\end{array}$ & $\begin{array}{l}\text { TACE significantly improved } \\
\text { survival in select patients }\end{array}$ \\
\hline
\end{tabular}

WHO=World Health Organization; EASL=European Association for the Study of the Liver.

for TACE compared with symptomatic treatment alone in selected patients with unresectable HCC and preserved liver function [19, 20]; however, a more recent Cochrane meta-analysis failed to find evidence of a survival benefit [20]. Table 1 details the results of a literature review on TAE for HCC.

An unresolved issue in the treatment of HCC with TACE/TAE is the timing of repeat treatment. In clinical practice, it remains difficult to predict the failure of such retreatments. Moreover, even the definition of refractory TACE/TAE is still unclear. To address this problem, scoring systems have been proposed to help physicians to identify patients who will not profit from retreatment with TACE. Among these scores, the assessment for retreatment with TACE score seems to be one of the most promising [21]. The accurate review of the imaging findings after TAE/TACE still remains one of the most important steps in interpreting the results of the procedures [22].

Another important open issue in the treatment of HCC with TACE/TAE is the association between these therapies and sorafenib. Recently, Lencioni et al. [23] reported that the use of TACE with doxorubicin-eluting beads plus sorafenib did not improve patient survival over TACE alone. Despite these negative results, further studies on the benefit of combined therapy should be undertaken.

Complications from liver embolization may include upper quadrant pain, nausea, moderate ileus, fatigue, fever, and transient elevations of asparate aminotransferase, alanine aminotransferase, and bilirubin levels. Symptoms are usually self-limiting and may be worsened by the use of chemotherapy in TACE $[20,24]$. Serious complications such as hepatic failure, gastroduodenal ulceration, kidney failure, and death (2-3\%) have been reported at very low percentages [3]. 


\section{Predictors of Response to TACE/TAE Treatments: The Western Perspective}

TACE and TAE promote local disease control through tumor necrosis and apoptosis induced by hypoxic and cytotoxic agents. Although potentially very useful in optimizing patient selection and follow-up, the individual response to TACE is generally unpredictable [19]. Investigators from both Eastern and Western countries have proposed several prognostic indices, based on combinations of clinical and laboratory parameters, to help clinicians select appropriate candidates for initial or repeat TACE or TAE. Unfortunately, no prognostic index is today universally accepted because they are difficult to implement, insufficiently discriminatory, or present methodological problems [25]. Such studies essentially identify a set of parameters that appear to maximize predictive performance, but this predictive performance cannot be repeated elsewhere because of random fluctuations of patient characteristics and differences in clinical management and the technical execution of TACE and TAE. This fact suggests that studies with larger target populations are needed [25]. Moreover, the sensitivity of HCC to transarterial therapy may also vary according to the tumor biology, but very few studies have focused on the predictive value of tumor morphological or molecular markers of response to TACE or TAE.

A study conducted in Italy and France investigated the association of post-TACE tumor necrosis, as assessed in surgical specimens, with the immunohistochemical expression of biomarkers involved in adaptive mechanisms to hypoxia that are hypothetically able to influence the response to TACE [26]. The markers selected in this study were hypoxia-inducible factor 1- $\alpha$ (HIF1 $\alpha$ ) and vascular endothelial growth factor (VEGF) for neoangiogenesis, CD34 for microvessel density, CA9 for antiapoptotic activity, CD133 and nestin for stem cell features, and vimentin and E-cadherin for the epithelial-mesenchymal transition (EMT); all these markers have previously been identified as being related to treatment resistance in several types of malignancies [27-30]. In the above study, multivariate analysis found that only CD34 and VEGF retained a significant association with TACE response [26]. A typical pattern of expression (VEGF-, CD34+) was associated with resistance to TACE, suggesting that HCCs with this expression pattern are more resistant to hypoxia because they have already developed a complete vascular network (increased CD34) without requiring further neoangiogenesis (decreased VEGF). This finding was also confirmed based on the results of pretreatment liver biopsies and their correlation with the radiological evaluation of responses to TACE.

These data suggest that further investigations are needed on the role of HCC biology in influencing responses to TACE, in particular because easily applicable and validated predictors of response to treatment are currently lacking. Prototypical characteristics of these markers have recently been proposed: ideally, they should be cost-effective, reproducible, and easy to evaluate also on pretreatment specimens, such as liver biopsy or liquid biopsy specimens [31].

\section{Predictors of Response to Intra-Arterial Treatment: The Eastern Perspective}

TACE induces marked ischemic tumor necrosis by obstructing tumor-feeding arteries with a chemotherapeutic agent emulsified with Lipiodol and embolic agents. However, a significant number (50-86\%) of HCCs show residual viable tumor [32]. To adapt and survive in a hypoxic tumor microenvironment, cancer cells express hypoxia-inducible factors, including HIF $1 \alpha$, to activate target genes involved in proliferation, angiogenesis, and EMT, resulting in a more aggressive tumor phenotype [33]. Hypoxia is reportedly important in reprogramming cancer cells to a cancer stem cell phenotype, which plays an important role in tumor 
maintenance and recurrence [34]. HCCs that express stemness-related markers, such as K19, EpCAM, or CD133, are known to have aggressive biological behavior with poorer prognosis compared to HCCs not expressing these markers [35]. Hepatitis B virus (HBV) is the main etiology of HCC in Eastern countries, and, recently, Hepatitis B protein x (HBx) antigen was reported to enhance hypoxia signaling through HIF1 $\alpha$ activation and to enhance EpCAM expression by activating $\beta$-catenin and regulating EpCAM promoter methylation [35]. Thus, HBx is suggested to be an additional player in the promotion of the switch in gene expression to stemness in hepatocarcinogenesis, especially in hypoxic tumor microenvironments.

To study the effect of stemness on the TACE response, the authors (HR and YNP) evaluated the transcript levels of hypoxia- (HIF1A), stemness- (EPCAM, KRT19, POU5F1, NANOG), and EMT-related (SNAI1, TWIST1) markers by real-time reverse-transcription polymerase chain reaction in HBV-related progressed HCCs that had and had not undergone preoperative TACE; totally necrotic HCCs after TACE were excluded [unpublished data]. Residual HCCs that had undergone preoperative TACE exhibited upregulation of HIF1A and SNAI1 mRNA compared to those that had not undergone preoperative TACE. HCCs with high HIF1A mRNA levels showed greater transcription levels of stemness- and EMT-related markers, more invasive pathological features, and poorer outcomes than those with low HIF1A mRNA levels. Therefore, stemness is considered to be involved with TACE resistance via upregulation of HIF1A. Consequently, controlling stemness is suggested to be important to increase the TACE response of HBV-related HCC. Further studies are needed to validate and confirm our findings.

\section{Conclusions}

TACE and TAE are two widely used therapies for HCC. Recent refinements in interventional radiology techniques have facilitated better local control, and TARE is rapidly emerging as an alternative therapy, thereby further expanding the indications for intra-arterial therapies. Further refinement of the patient selection criteria will optimize the use and role of such treatments. In the future, the molecular profiling of HCC to predict the response to TACE and TAE will help clinicians select the optimum treatment.

\section{Conflicts of Interest}

The authors declare that no conflicts of interest exist.

\section{References}

1 European Association for the Study of the Liver and the European Organisation for Research and Treatment of Cancer: EASL-EORTC clinical practice guidelines: management of hepatocellular carcinoma. J Hepatol 2012;56:908-943.

2 Sangro B, Carpanese L, Cianni R, Golfieri R, Gasparini D, Ezziddin S, Paprottka PM, Fiore F, Van Buskirk M, Bilbao JI, Ettorre GM, Salvatori R, Giampalma E, Geatti O, Wilhelm K, Hoffmann RT, Izzo F, Iñarrairaegui M, Maini CL, Urigo C, Cappelli A, Vit A, Ahmadzadehfar H, Jakobs TF, Lastoria S, European Network on Radioembolization with Yttrium-90 Resin Microspheres (ENRY): Survival after yttrium-90 resin microsphere radioembolization of hepatocellular carcinoma across Barcelona clinic liver cancer stages: a European evaluation. Hepatology 2011;54:868-878.

3 Marelli L, Stigliano R, Triantos C, Senzolo M, Cholongitas E, Davies N, Tibballs J, Meyer T, Patch DW, Burroughs AK: Transarterial therapy for hepatocellular carcinoma: which technique is more effective? A systematic review of cohort and randomized studies. Cardiovasc Intervent Radiol 2007;30:6-25. 
4 Yamada R, Sato M, Kawabata M, Nakatsuka H, Nakamura K, Takashima S: Hepatic artery embolization in 120 patients with unresectable hepatoma. Radiology 1983;148:397-401.

5 Nakamura H, Hashimoto T, Oi H, Sawada S: Transcatheter oily chemoembolization of hepatocellular carcinoma. Radiology 1989;170:783-786.

6 Uchida H, Ohishi H, Matsuo N, Nishimine K, Ohue S, Nishimura Y, Maeda M, Yoshioka T: Transcatheter hepatic segmental arterial embolization using lipiodol mixed with an anticancer drug and Gelfoam particles for hepatocellular carcinoma. Cardiovasc Intervent Radiol 1990;13:140-145.

7 Matsui O, Kadoya M, Yoshikawa J, Gabata T, Arai K, Demachi H, Miyayama S, Takashima T, Unoura M, Kogayashi K: Small hepatocellular carcinoma: treatment with subsegmental transcatheter arterial embolization. Radiology 1993;188:79-83.

8 Tsurusaki M, Murakami T: Surgical and locoregional therapy of HCC: TACE. Liver Cancer 2015;4:165-175.

9 Bonomo G, Pedicini V, Monfardini L, Della Vigna P, Poretti D, Orgera G, Orsi F: Bland embolization in patients with unresectable hepatocellular carcinoma using precise, tightly size-calibrated, anti-inflammatory microparticles: first clinical experience and one-year follow-up. Cardiovasc Intervent Radiol 2010;33:552-559.

10 Brown DB, Geschwind JF, Soulen MC, Millward SF, Sacks D: Society of Interventional Radiology position statement on chemoembolization of hepatic malignancies. J Vasc Interv Radiol 2006;17:217-223.

11 Brown DB, Pilgram TK, Darcy MD, Fundakowski CE, Lisker-Melman M, Chapman WC, Crippin JS: Hepatic arterial chemoembolization for hepatocellular carcinoma: comparison of survival rates with different embolic agents. J Vasc Interv Radiol 2005;16:1661-1666.

12 Carr BI, Kondragunta V, Buch SC, Branch RA: Therapeutic equivalence in survival for hepatic arterial chemoembolization and yttrium 90 microsphere treatments in unresectable hepatocellular carcinoma: a two-cohort study. Cancer 2010;116:1305-1314.

13 Salem R, Lewandowski RJ, Mulcahy MF, Riaz A, Ryu RK, Ibrahim S, Atassi B, Baker T, Gates V, Miller FH, Sato KT, Wang E, Gupta R, Benson AB, Newman SB, Omary RA, Abecassis M, Kulik L: Radioembolization for hepatocellular carcinoma using yttrium-90 microspheres: a comprehensive report of long-term outcomes. Gastroenterology 2010;138:52-64.

14 Mazzaferro V, Sposito C, Bhoori S, Romito R, Chiesa C, Morosi C, Maccauro M, Marchianò A, Bongini M, Lanocita R, Civelli E, Bombardieri E, Camerini T, Spreafico C: Yttrium-90 radioembolization for intermediate-advanced hepatocellular carcinoma: a phase 2 study. Hepatology 2013;57:1826-1837.

15 Zhang Y, Li Y, Ji H, Zhao X, Lu H: Transarterial Y90 radioembolization versus chemoembolization for patients with hepatocellular carcinoma: a meta-analysis. Biosci Trends 2015;9:289-298.

16 Braat AJ, Huijbregts JE, Molenaar IQ, Borel Rinkes IH, van den Bosch MA, Lam MG: Hepatic radioembolization as a bridge to liver surgery. Front Oncol 2014;4:199.

17 Teo JY, Allen JC Jr, Ng DC, Choo SP, Tai DW, Chang JP, Cheah FK, Chow PK, Goh BK: A systematic review of contralateral liver lobe hypertrophy after unilobar selective internal radiation therapy with Y90. HPB Oxf 2016;18:7-12.

18 Llovet JM, Real MI, Montaña X, Planas R, Coll S, Aponte J, Ayuso C, Sala M, Muchart J, Solà R, Rodés J, Bruix J, Barcelona Liver Cancer Group: Arterial embolisation or chemoembolisation versus symptomatic treatment in patients with unresectable hepatocellular carcinoma: a randomised controlled trial. Lancet 2002;359:1734-1739.

19 Lo CM, Ngan H, Tso WK, Liu CL, Lam CM, Poon RT, Fan ST, Wong J: Randomized controlled trial of transarterial lipiodol chemoembolization for unresectable hepatocellular carcinoma. Hepatology 2002;35:11641171.

20 Malagari K, Pomoni M, Kelekis A, Pomoni A, Dourakis S, Spyridopoulos T, Moschouris H, Emmanouil E, Rizos S, Kelekis D: Prospective randomized comparison of chemoembolization with doxorubicin-eluting beads and bland embolization with BeadBlock for hepatocellular carcinoma. Cardiovasc Intervent Radiol 2010;33:541-551.

21 Sieghart W, Hucke F, Pinter M, Graziadei I, Vogel W, Müller C, Heinzl H, Trauner M, Peck-Radosavljevic M: The ART of decision making: retreatment with transarterial chemoembolization in patients with hepatocellular carcinoma. Hepatology 2013;57:2261-2273.

22 Vincenzi B, Di Maio M, Silletta M, D’Onofrio L, Spoto C, Piccirillo MC, Daniele G, Comito F, Maci E, Bronte G, Russo A, Santini D, Perrone F, Tonini G: Prognostic relevance of objective response according to EASL criteria and mRECIST criteria in hepatocellular carcinoma patients treated with loco-regional therapies: a literature-based meta-analysis. PLoS One 2015;10:e0133488.

23 Lencioni R, Llovet JM, Han G, Tak WY, Yang J, Guglielmi A, Paik SW, Reig M, Kim Y, Chau GY, Luca A, del Arbol LR, Leberre MA, Niu W, Nicholson K, Meinhardt G, Bruix J: Sorafenib or placebo plus TACE with doxorubicin-eluting beads for intermediate stage HCC: The SPACE trial. J Hepatol 2016;64:1090-1098.

24 Facciorusso A, Licinio R, Muscatiello N, Di Leo A, Barone M: Transarterial chemoembolization: evidences from the literature and applications in hepatocellular carcinoma patients. World J Hepatol 2015;7:20092019.

25 Sciarra A, Ronot M, Di Tommaso L, Raschioni C, Castera L, Belghiti J, Bedossa P, Vilgrain V, Roncalli M, Paradis V: TRIP: a pathological score for transarterial chemoembolization resistance individualized prediction in hepatocellular carcinoma. Liver Int 2015;35:2466-2473.

26 Huang GW, Yang LY, Lu WQ: Expression of hypoxia-inducible factor 1alpha and vascular endothelial growth factor in hepatocellular carcinoma: Impact on neovascularization and survival. World J Gastroenterol 2005;11:1705-1708. 
27 Poon RT, Ng IO, Lau C, Yu WC, Yang ZF, Fan ST, Wong J: Tumor microvessel density as a predictor of recurrence after resection of hepatocellular carcinoma: a prospective study. J Clin Oncol 2002;20:1775-1785.

28 Marie-Egyptienne DT, Lohse I, Hill RP: Cancer stem cells, the epithelial to mesenchymal transition (EMT) and radioresistance: potential role of hypoxia. Cancer Lett 2013;341:63-72.

29 Yang XR, Xu Y, Yu B, Zhou J, Qiu SJ, Shi GM, Zhang BH, Wu WZ, Shi YH, Wu B, Yang GH, Ji Y, Fan J: High expression levels of putative hepatic stem/progenitor cell biomarkers related to tumour angiogenesis and poor prognosis of hepatocellular carcinoma. Gut 2010;59:953-962.

30 Torbenson M, Schirmacher P: Liver cancer biopsy-back to the future?! Hepatology 2015;61:431-433.

31 Chua TC, Liauw W, Saxena A, Chu F, Glenn D, Chai A, Morris DL: Systematic review of neoadjuvant transarterial chemoembolization for resectable hepatocellular carcinoma. Liver Int 2010;30:166-174.

32 Semenza GL: Targeting HIF-1 for cancer therapy. Nat Rev Cancer 2003;3:721-732.

33 Heddleston JM, Li Z, McLendon RE, Hjelmeland AB, Rich JN: The hypoxic microenvironment maintains glioblastoma stem cells and promotes reprogramming towards a cancer stem cell phenotype. Cell Cycle 2009;8:3274-3284.

34 Kim H, Choi GH, Na DC, Ahn EY, Kim GI, Lee JE, Cho JY, Yoo JE, Choi JS, Park YN: Human hepatocellular carcinomas with "Stemness"-related marker expression: keratin 19 expression and a poor prognosis. Hepatology 2011;54:1707-1717.

35 Arzumanyan A, Friedman T, Ng IO, Clayton MM, Lian Z, Feitelson MA: Does the hepatitis B antigen HBx promote the appearance of liver cancer stem cells? Cancer Res 2011;71:3701-3708. 